\title{
Nutritional aspects of exercise-induced fatigue
}

\section{By Clyde Williams, Department of Physical Education and Sports Science, University of Technology, Loughborough, Leics. $L E_{1}$ I $3 T U$}

Fatigue during exercise is a common experience irrespective of the level of activity and it is manifest as a decrease in exercise tolerance. This decreased exercise tolerance is most dramatically illustrated during various athletic competitions. For example, the runner who completes a marathon race is not only moving much more slowly than earlier in the race, but also crosses the finishing line with only the minimum of physical coordination. The onset of fatigue is even more dramatically illustrated by sprinters who as they fatigue towards the end of their race make their fellow athletes, who are also slowing down but less rapidly, appear to accelerate past them towards the finishing line. In sports which require skills of coordination, such as tennis, cricket or football, as fatigue develops so skill disappears and thus, what to the unfatigued spectators is still an 'easy shot, move, pass or catch' is not recognized as such by the participant. Fatigue is then readily recognized and experienced at the whole-body level. However, the physiological explanations for fatigue are not so readily available because of the complexity of the phenomena. In this presentation therefore, the metabolic aspects of fatigue in skeletal muscles during exercise will be the focus of attention rather than, for example, the contributions to fatigue, from interactions within the central nervous system. Apart from exercise which demands maximum exertion over a few seconds, fatigue may be regarded as having metabolic origins in the sense that it may be simply described as a mismatching of the rates of ATP utilization and resynthesis in skeletal muscles. This imbalance between the rates of demand and supply of ATP is redressed by decreasing the demand for ATP, i.e. by slowing down, which has various levels of acceptability depending on the urgency with which the activity has to be completed.

\section{Exercise intensity}

During exercise which can be sustained for a prolonged period of time, such as walking or slow running, the energy needs of the working muscles are covered by aerobic metabolism. The energy expenditure can be estimated from a determination of the person's oxygen uptake $\left(\dot{V}_{\mathrm{O}_{2}}\right)$. The $\dot{V}_{\mathrm{O}_{2}}$ of an individual increases linearly with an increase in exercise intensity until a point is reached at which there is no further increase in $\dot{V}_{\mathrm{O}_{2}}$ (Fig. I). The levelling off of the $\dot{V}_{\mathrm{O}_{2}}$ is called the maximum $\mathrm{O}_{2}$ uptake $\left(\dot{\mathrm{V}}_{2}\right.$ max $)$, and is a reflection of the individual's cardiovascular capacity for $\mathrm{O}_{2}$ transport (Rowell, 1974). The $\dot{V}_{\mathrm{O}_{2} \max }$ provides information about the levels of exercise an individual may be able to sustain (Williams, 1981; Williams \& Nute, 1983). Furthermore when the $\mathrm{O}_{2}$ cost of an activity is expressed as a percentage of the individual's $\dot{V}_{\mathrm{O}_{2} \max }\left(\% \dot{V}_{\mathrm{O}_{2} \max }\right)$ then 


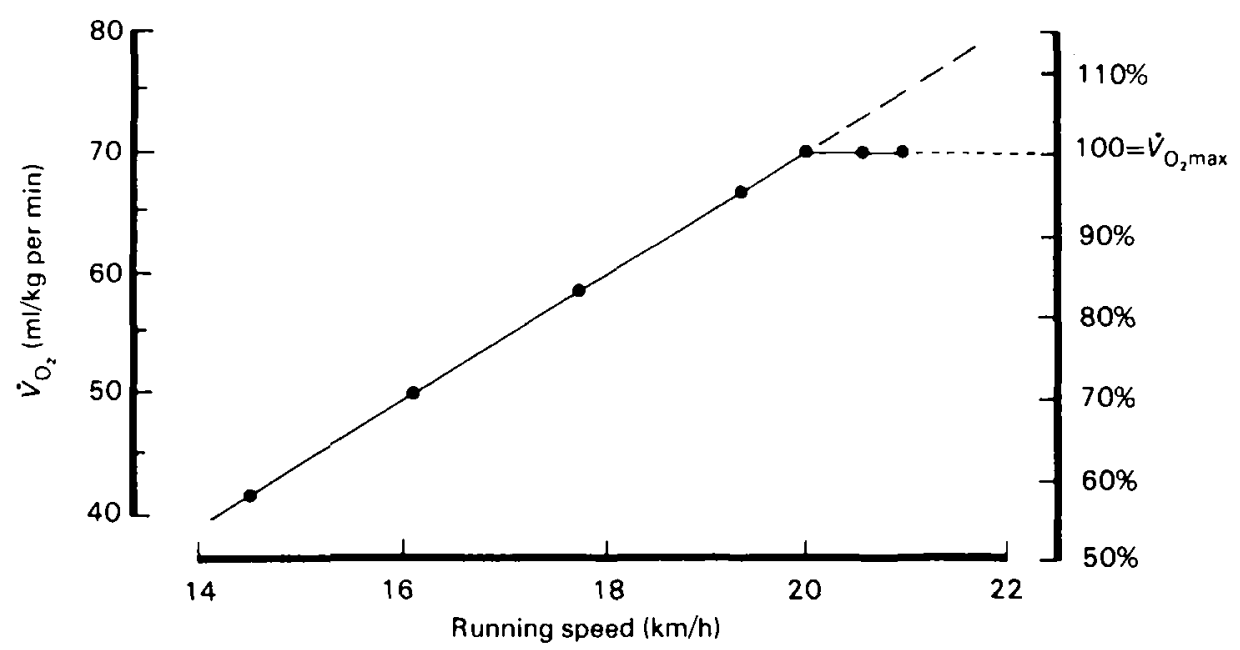

Fig. I. A schematic representation of the relation between the oxygen cost $\left(\dot{V}_{\mathrm{O}_{2}}\right)$ of running at various speeds. Running speeds have also been expressed as $\% \dot{V}_{\mathrm{O}_{2} \max }$.

this provides an indication of the relative exercise intensity or the physiological stress on the individual. The cardiovascular adjustments to exercise occur with respect to the relative exercise intensity rather than the absolute exercise intensity. For example, when a group of individuals are performing the same amount of exercise, walking or running at the same speed, their cardiovascular responses will depend on what $\% \dot{V}_{\mathrm{O}_{2} \max }$ the exercise represents for them, even though the external work is the same for the group as a whole. In addition the thermoregulatory response to exercise follows the same general rule, in that the rise in core temperature is proportional, not to the external exercise intensity but, to the $\% \dot{V} \mathrm{O}_{2 \max }$ which it represents for the individual (Rowell, 1974). Therefore in attempting to study the metabolic responses to exercise and understand the phenomena of fatigue it is essential that these concepts are recognized and employed in the design of experiments.

\section{Fatigue during prolonged exercise}

The early studies of Krogh \& Lindhard, (1920) and Christensen \& Hansen (1939) have established that during prolonged exercise the relative contributions of carbohydrate and fat to energy metabolism shifts from mainly carbohydrate to an increase in fat metabolism towards the end of exercise. Furthermore these studies have also shown that during exercise of increasing intensity there is an ever increasing contribution from carbohydrate to energy metabolism. Recent studies, using more sophisticated techniques for studying metabolism than the respiratory exchange ratios, have confirmed and extended these basic guidelines on metabolism during exercise (Jansson, 1982).

Fatigue during prolonged exercise is associated with the depletion or reduction of skeletal muscle glycogen concentration as has been shown in experiments using a percutaneous needle biopsy technique to obtain samples of human muscle 
(Bergström \& Hultman, 1966; Ahlborg et al. 1967a,b; Hermansen et al. 1967; Gollnick et al. 1969 ). In contrast a study of the ultrastructure of skeletal muscles of laboratory rats, killed after prolonged treadmill running to exhaustion, suggested that fatigue may have been the result of mitochondrial disruption (Gollnick \& King, I 969). An examination of skeletal muscle by electron microscopy had shown that the mitochondrial cristae were disrupted and implied that oxidative phosphorylation may have been seriously impaired. A subsequent study, in which the ultrastructural changes in human skeletal muscle were examined, showed that prolonged exhaustive exercise produced only the disappearance of intramuscular glycogen granules and had no disruptive effect on the mitochondrial cristae (Gollnick et al. 1969). This latter experiment therefore confirmed the biochemical studies which had shown the association between glycogen depletion and fatigue. A closer examination of glycogen depletion in human skeletal muscles, following prolonged exercise, has been possible by using histochemical techniques to identify different muscle fibres and their glycogen concentrations.

\section{Muscle fibre types}

Human muscle fibres have been classified according to their myosin ATPase (EC 3.6.1.3) activities (Padykula \& Herman, 1955) which have been shown to be broadly related to their speeds of contraction (Barany, 1967). The two groups of fibre types recognized by the qualitative histochemical technique are called type I and type II (Brooke \& Kaiser, 1970). Type I fibres have lower myosin ATPase activity than type II fibres and are slower to contract and slower to fatigue. The greater endurance capacity of the type I fibres may be explained by their greater oxidative capacity and therefore their ability to cover their energy needs by aerobic metabolism of glycogen and fatty acids. The process of oxidative metabolism is aided by the greater capillarization of type I fibres compared with type II fibres (Andersen, 1975; Inger, 1979). The type II fibres have a higher myosin ATPase activity than type I fibres but contract and fatigue more quickly than type I fibres (Burke et al. 1971; Essen et al. 1975). Type II fibres also have a lower mitochondrial density and so a lower aerobic capacity than the type I fibres. As a consequence of their lower aerobic capacity, the type II fibres rely on anaerobic degradation of glycogen for ATP resynthesis to a greater extent than do the type I fibres and, as such, tend to be the 'lactate producing' fibres (Essen et al. 1975). The type II fibres can be divided into two sub-groups, namely type IIA and type IIB. Formerly this distinction was made on the basis of the greater oxidative capacity of the type IIA fibres compared with that of the type IIB fibres (Anderson \& Henriksson, 1977). The latter sub-group has been referred to as typical "white muscle' in that these fibres are fast to contract and fast to fatigue, whereas the type IIA fibres are less liable to fatigue. The two sub-groups of type II fibres have recently been shown to have separate identities on the basis of their different populations of myosin light chains (Billeter et al. 1980, 1981). Therefore the type IIA fibres are not simply type IIB fibres with greater oxidative capacities as was formerly suggested. 
The recruitment pattern of these different fibre types, during exercise of gradually increasing intensity, appears to follow the size principle proposed by Henneman \& Olson (1965) in that the similar diameter motor nerves innervating the type I fibres are activated before the larger motor nerves which innervate the type II fibres. Gollnick et al. (1973) have used histochemical staining procedures for glycogen on muscle samples obtained before and after exercise of various intensities, to study fibre recruitment on the basis that the fibres with a decreased staining intensity are those recruited most frequently during exercise. Thus using these procedures they have shown that during prolonged exercise the type I and type IIA fibres are recruited first and glycogen depleted in advance of the type IIB fibres (Gollnick et al. 1975). The decrease in the glycogen concentration of the muscle fibres leads to their inability to contract at the required rate and so this may signal the need to recruit other motor units in order that the exercise intensity may be sustained (Gollnick et al. 1975). It should be noted however that these studies, which have increased our understanding of muscle fibre recruitment during exercise, are based on experiments in which exercise was performed on bicycle ergometers. Bicycle ergometry provides an excellent exercise model for the study of human muscle metabolism because the quadriceps muscles are almost entirely responsible for the generation of external work. This form of exercise is highly reproducible and there is little inter-individual difference in the $\mathrm{O}_{2}$ cost per unit of power output ( $\AA$ strand \& Rodahl, 1977). In contrast, treadmill or free running allows greater inter-individual variability in the $\mathrm{O}_{2}$ cost of running at different speeds and also the freedom to change gait, which is not available to individuals exercising on bicycle ergometers. This freedom to distribute the work load over a larger muscle mass and to be able to change gait during the onset of fatigue may explain why muscle glycogen concentrations are rarely as low at the end of a run to exhaustion as they are after cycling to exhaustion (Karlsson \& Saltin, 1971; Gollnick, et al. 1975). These observations raise the question about the cause of fatigue during running as compared with cycling to exhaustion and while the precise answer to this question is unavailable, it may be assumed that the reduced muscle glycogen stores contribute significantly to the decreased exercise tolerance.

\section{Metabolism during exercise}

Endurance capacity is then limited by the apparent shortage of carbohydrate, mainly in the form of muscle glycogen. Skeletal muscle glycogen concentrations range between 60 and $120 \mathrm{mmol}$ glucosyl units $/ \mathrm{kg}$ wet weight (Bergström et al. 1967; Piehl, 1974; Costill et al. 1977). The higher values are those from endurance athletes and it seems that endurance training per se increases the muscle's store of glycogen. The other major storage site of glycogen is the liver, which after a normal meal would contain approximately $600 \mathrm{mmol}$ glucosyl units $/ \mathrm{kg}$ wet weight or approximately $1100 \mathrm{mmol}$ glucosyl units for an adult liver weighing about $\mathrm{I} \cdot 8$ $\mathrm{kg}$ (Nilsson \& Hultman, 1973). The role of liver glycogen is to maintain blood glucose concentrations within the normal range, so as to ensure an adequate supply for the metabolic requirements of the central nervous system and the brain. While 
Table I. Muscle glycogen concentrations (mmol/kg wet weight) of vastus lateralis of untrained and trained subjects, before and after 24 h of fasting

(Mean values with their standard errors)

\begin{tabular}{|c|c|c|c|c|}
\hline \multirow[b]{2}{*}{ Subjects } & \multicolumn{2}{|c|}{ Fed } & \multicolumn{2}{|c|}{ Fasting } \\
\hline & Mean & $\widehat{\text { SEM }}$ & & SEM \\
\hline $\begin{array}{l}\text { Untrained }(n 6) \\
\text { Trained distance }\end{array}$ & $57 \cdot 7$ & 49 & $60 \cdot 7$ & $7 \cdot 7$ \\
\hline runners $\left(n_{4}\right)$ & $9 \mathrm{I} \cdot 2$ & $8 \cdot 5$ & $85 \cdot 0$ & $12 \cdot 1$ \\
\hline
\end{tabular}

liver glycogen concentration fluctuates between meals and its concentration is reduced by half after an overnight fast, skeletal muscle glycogen is less vulnerable to fasting (Table I). Skeletal muscie glycogen does not contribute directly to glucose homeostasis but does so indirectly through the provision of its metabolites lactate, pyruvate and alanine as precursors for gluconeogenesis in the liver.

In spite of decreased insulin concentrations during exercise, which is mediated by the rise in catecholamines, glucose does enter muscle cells and add to the carbohydrate stores of muscles (Galbo et al. 1979). During prolonged low intensity exercise $\left(30 \% \dot{V}_{\mathrm{O}_{2} \max }\right)$ blood glucose may contribute as much as $40 \%$ to muscle metabolism (Ahlborg et al. 1974). It is as yet uncertain how much blood glucose contributes to muscle metabolism during prolonged exercise of higher intensities (e.g. $70 \% \dot{V}_{\mathrm{O}_{2} \max }$ ). Ingestion of a glucose solution at the point of fatigue, during prolonged exercise, has been shown to extend exercise time without increasing overall carbohydrate combustion (Christensen \& Hansen, 1939). This effect was attributed to the removal of hypoglycaemia by the ingested glucose; however, in more recent studies in which a glucose solution was infused into runners at exhaustion, hypoglycaemia was corrected without an improvement in performance time (Galbo et al. 1979). More recent studies have shown that ingestion of glucose solutions throughout a period of exercise of moderate intensity $\left(60-65 \% \dot{V}_{\mathrm{O}_{2} \max }\right)$, prevents hypoglycaemia without changing the endurance time (Felig et al. 1982). Glucose ingested before prolonged exercise increases the plasma insulin concentration and hence the quantity of glucose metabolized during exercise, but paradoxically it also increases the amount of glycogen degraded (Ahlborg \& Felig, 1976, 1977; Costill et al. 1977). The increased glycogen utilization during exercise, following glucose ingestion, is a consequence of the decreased plasma fatty acid concentrations brought about by the antilipolytic effect of raised plasma insulin concentrations (Costill et al. 1977). Thus attempting to add to the limited carbohydrate stores of the body, by ingesting a glucose solution within an hour of the start of exercise, probably decreases endurance performance because of the subsequent increase in the rate of glycogen metabolism.

Although the carbohydrate stores are limited, there is an abundance of fatty acids for muscle metabolism during exercise. The uptake and utilization of fatty acids by skeletal muscle is mainly determined by their plasma concentration (Hagenfeldt \& Wahren, 197I; Gollnick, 1977). During prolonged submaximal 
exercise plasma free fatty acid concentrations increase in step with their mobilization from white adipose tissue cells and they make an ever increasing contribution to muscle metabolism at a time when carbohydrate stores are reduced (Gollnick, 1977). However, when the glycogen metabolism is reduced below a certain critical rate, because of inadequate glycogen stores in active muscle fibres, fatigue ensues in spite of the abundance of fatty acids. The inability of fat metabolism to bear a greater responsibility for muscle metabolism under these conditions is probably due to the relatively slow rate of ATP resynthesis when supported by fatty acid oxidation compared with the oxidation of carbohydrate (McGilvery, 1975). The limitation is then, not with the availability of fatty acids as substrates but with the oxidative capacity of the muscle fibres, which is too small to take advantage of the available and abundant fuel supply. Training increases the aerobic capacity of skeletal muscles and therefore allows fat metabolism to support a larger proportion of ATP resynthesis during exercise (Henriksson, 1977).

The presence of elevated plasma fatty acid concentrations, at the start of exercise, has a glycogen-sparing effect and increases endurance capacity. This effect of increased fat metabolism has been shown by elevating plasma fatty acids by administering before exercise a fatty meal and heparin or even caffeine (Hickson et al. 1977; Costill et al. 1978; Ivy et al. 1979). The mechanism by which the increased fatty acid metabolism exerts a glycogen-sparing effect is suggested as operating through the influence of the citrate sensitivity of the enzyme phosphofructokinase (EC 2.7.1.1 I) which is prominent in the control of glycogenolysis (Newsholme \& Start, 1973). The elevated fatty acid metabolism produces an increase in citrate concentrations (Rennie et al. 1976) and citrate is able to pass through the mitochrondrial membrane and exert an inhibitory effect on phosphofructokinase in the sarcoplasm (Newsholme \& Start, 1973).

\section{Diet}

Of the two methods of increasing substrate availability for muscle metabolism during exercise, increasing the carbohydrate stores has a longer history of use in the preparation for endurance competitions than has the increase in plasma fatty acids. It is then, with respect to the adequacy of the muscle glycogen concentration before prolonged exercise that nutrition plays its most convincing role in helping delay the onset of fatigue.

The importance of a diet rich in carbohydrate as part of the preparation for endurance performance has been established by the studies of Krogh \& Lindhard (1920) and those of Christensen \& Hansen (1939). In the studies of Christensen \& Hansen (1939) each subject exercised on a bicycle ergometer at an exercise intensity equivalent to approximately $67 \% \dot{V}_{\mathrm{O}_{2} \max }$. After $3-4 \mathrm{~d}$ on a lowcarbohydrate diet, exercise time to exhaustion was $90 \mathrm{~min}$ whereas endurance time increased to $240 \mathrm{~min}$ after the same period of time on a high-carbohydrate diet. The influence of prolonged high-intensity exercise and subsequent consumption of a carbohydrate-rich diet on muscle glycogen concentrations has been clearly shown by Bergström \& Hultman (1966). In their now classical 'one leg' study they showed 
that when one leg is exercised to exhaustion only the muscle glycogen stores in the exercised leg experience glycogen depletion. Furthermore, when a carbohydraterich diet was consumed during the recovery period the glycogen stores were not only repleted but were almost double their pre-exercise values. This supercompensation phenomenon was confined to the muscles of the active leg and no such increase occurred in the inactive leg. In an attempt to exploit the supercompensation phenomenon, Ahborg et al. (1967a) showed that when glycogen depletion is followed by $3 \mathrm{~d}$ on a low-carbohydrate diet and then $3 \mathrm{~d}$ on a high-carbohydrate diet the supercompensation of muscle glycogen is most pronounced. An example of the changes in muscle glycogen concentrations following this type of exercise and dietary procedure is shown in Table 2. The more pronounced response of the endurance-trained subject RJM was probably due to the fact that he only reduced his training during the $3 \mathrm{~d}$ on the high-carbohydrate diet but not before. This combination of exercise and diet has been shown to improve endurance performance during exercise on a bicycle ergometer by between $3^{8}$ and $50 \%$ (Ahlborg et al. $1967 b$; Bergström et al. 1967; Williams et al. 1976). Most of the experimental work on the influence of dietary procedures for increasing muscle glycogen concentrations has been carried out using bicycle ergometers. Surprisingly little attention has been paid to the effectiveness of these dietary procedures on the endurance capacity during running, even though they have been recommended as part of the preparation for participation in endurance competitions (Åstrand, 1967). Running to exhaustion does not appear to reduce the muscle glycogen stores to the same extent as during cycle ergometry and may not therefore be so closely associated with the development of fatigue (Karlsson \& Saltin, 1971). Nevertheless, in one of the few studies on dietary carbohydrate loading and running performance Goforth et al. (1980) showed that at a running speed equivalent to $80 \% \dot{V}_{\mathrm{O}_{2} \max }$ the improvement in endurance capacity was only $9 \%$. More recently, improvements in treadmill running times of approximately $26 \%$ have been found using different forms of carbohydrate loading (Williams et al. 1985). In this study dietary carbohydrate loading was accomplished by supplementing the diets of the runners with either more of their habitual dietary carbohydrates, or simply by using confectionery

Table 2. Muscle glycogen concentrations ( $\mathrm{mmol} / \mathrm{kg}$ wet weight) of an untrained $(C W)$ and trained subject $(R \mathcal{F} M)$ before and after undertaking the glycogen-loading procedure (Ástrand, r 967)

$\begin{array}{ccc}\text { Subjects } & \begin{array}{c}\text { Normal } \\ \text { (mixed) } \\ \text { diet }\end{array} & \begin{array}{c}\text { Exercise to exhaustion } \\ \text { followed by 3 d on } \\ \text { a low-CHO diet }\end{array} \\ \text { CW } & 7^{2} & 45 \\ \text { RJM } & 5^{\bullet} & 4^{\circ}\end{array}$

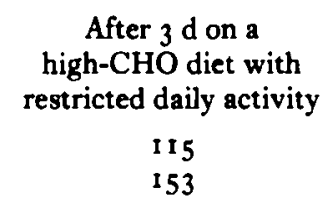

CHO, Carbohydrate.

-RJM did not decrease his training or alter his diet before providing a pre-exercise biopsy sample for glycogen analysis, at the beginning of this study on glycogen supercompensation. 
products. These dietary manipulations were performed during the $3 \mathrm{~d}$ following a treadmill run to exhaustion at speeds equivalent to $70 \% \dot{V}_{\mathrm{O}_{2} \max }$. Running time to exhaustion was improved after only $72 \mathrm{~h}$ of recovery and these dietary modifications.

While the available evidence supports the claims that dietary carbohydrate loading improves endurance performance there is only limited evidence to suggest that these procedures help improve performance times under race conditions. In the only reported study involving an endurance race $(30 \mathrm{~km})$, glycogen-loading before the race improved the performance times of the subjects by an average of 8 min or $5.6 \%$ (Karlsson \& Saltin, I97I). In this study, the speed of the subjects during the early part of the race did not increase after glycogen-loading, but they were able to sustain their optimal pace for longer during the latter part of the race. A closer examination of the results of this study reveals that the subjects could be divided into two groups, one group having higher $\dot{V}_{\mathrm{O}_{2} \max }$ values and faster race times than the other group. This first group was made up of experienced distance runners whereas the second group was of active physical education students. The reductions in the running time for the $30 \mathrm{~km}$ were $5 \mathrm{~min}(3.2 \%)$ and $12 \mathrm{~min}$ $(7.6 \%)$ for the first and second groups of runners respectively. The endurance runners had higher concentrations of muscle glycogen than the second group of subjects, and this may partly explain the difference in race times before and after the glycogen-loading procedures. The higher glycogen concentrations of the trained runners, without dietary modification, probably allowed them to sustain their optimal pace for more or less the entire race, hence the contribution of the dietary manipulation procedure was less effective for these individuals.

\section{Glycogen resynthesis}

The capacity for glycogen resynthesis in human skeletal muscle has been clearly shown by Bergström \& Hultman (1966) in their 'one leg' exercise study. In this study the glycogen concentration of the exercised leg increased by about twice its pre-exercise value. The conditions for this glycogen supercompensation are (a) an initial glycogen depletion and (b) a carbohydrate-rich diet during the post-exercise period. The mechanism(s) underlying this phenomenon are not completely understood but involve a conversion of the inactive glycogen synthetase D (EC 2.4. I.I I) to the active glycogen synthetase I form. An exercise-induced decrease in muscle glycogen also decreases the intramuscular concentrations of glucose-6phosphate and under these conditions the activity of synthetase I enzyme is at its highest (Danforth, 1965; Piras \& Staneloni, 1969). In a series of studies by Holloszy and co-workers (Holloszy, 1984) on glycogen resynthesis it has been shown that glucose uptake by the glycogen-depleted muscle is enhanced during the post-exercise recovery period. The post-exercise glucose uptake by muscle occurs in the fed and the fasted state and takes preference over the restoration of liver glycogen (Fell et al. 1980). Glycogen resynthesis is most rapid during the immediate post-exercise period (Hermansen \& Vaage, 1977; Chen et al. 1977). This is not only because of the increased activity of glycogen synthetase I, but also 
because of an exercise-induced increased permeability of muscle to glucose (Holloszy \& Narahara, 1965; Fell et al. 1980). Thus the conditions necessary for glycogen supercompensation appear to include exercise-induced depletion of muscle glycogen, which produces an increase in the activity of glycogen synthetase $I$ and also increases the permeability of muscle to glucose, along with a carbohydrate-rich diet to provide the necessary substrate for glycogen resynthesis, which in turn stimulates an increase in plasma insulin concentration and so enhances the glucose uptake by the muscle.

The question of speed of glycogen resynthesis is raised when individuals have to perform prolonged exercise on successive days. Piehl (1974) examined the rate of glycogen repletion in a group of trained subjects and reported that pre-exercise muscle glycogen concentrations were achieved only after $46 \mathrm{~h}$ of recovery during which time a carbohydrate-rich diet was consumed. The pre-exercise glycogen concentrations of the trained subjects in Piehl's (1974) study were at the top-end of the reported range and this may explain the delay in glycogen resynthesis. Untrained subjects, non-diabetic as well as insulin-treated diabetic subjects have been reported to have restored their pre-exercise glycogen concentrations after only $\mathrm{I} 2 \mathrm{~h}$ of recovery which included an increased carbohydrate intake (Maehlum et al. 1977). The glycogen resynthesis rates for the non-diabetic subjects and for the insulin-treated diabetics, calculated for the first $4 \mathrm{~h}$ of recovery were $7 \cdot 2$ $\mathrm{mmol} / \mathrm{kg}$ wet weight per $\mathrm{h}$, and $6 \cdot 2 \mathrm{mmol} / \mathrm{kg}$ wet weight per $\mathrm{h}$ respectively. These values are similar to those of the trained subjects in Piehl's (1974) study. In a recent study of glycogen depletion and repletion after a marathon race, the glycogen stores did not reach pre-marathon values even after I week of recovery (Sherman et al. 1983). Again the explanation may be related to the fact that many of the subjects in these experiments have 'glycogen loaded' by tapering their training and increasing their carbohydrate intake during the few days before the experiments or races (Sherman, 1983). This latter point is illustrated by the glycogen concentration shown in Table 2 for an untrained and trained subject. As a general guideline to glycogen replacement over $24 \mathrm{~h}$, Costill et al. (198I) have proposed that the dietary carbohydrate intake should be of the order of $500 \mathrm{~g}$ or approximately $70 \%$ of the daily energy intake for adult males. When different concentrations of glucose solutions are administered during the recovery period, in an attempt to enhance glycogen loading it appears that ingesting more than about $200 \mathrm{~g}$ over the first $8 \mathrm{~h}$ has little influence on the amount of glycogen resynthesized under these conditions and produces the same rates of resynthesis as in Piehl's (1974) study (Blom et al. 1984).

Fatigue during a brief period of maximum exercise is associated with a decrease in intramuscular $\mathrm{pH}$ rather than with glycogen depletion (Sahlin, 1978). Although glycogenolysis occurs at a rapid rate it is unable to proceed to the point where glycogen stores are limiting (Boobis et al. 1983 ). However, repeated brief periods of exercise of maximum intensity do make inroads into the limited glycogen stores of muscle as has been shown after bicyle ergometer exercise (MacDougall et al. 1977) and after a football match (Jacobs et al. 1982). Muscle samples obtained 
from football players after a match averaged $46 \mathrm{mmol} / \mathrm{kg}$ per wet weight, which suggested that football, which may be regarded as a multiple sprint sport, reduced the muscle glycogen concentrations to about half their normal pre-exercise values (Jacobs et al. 1982). What was surprising about the results from this informative study was that after $2 \mathrm{~d}$ of recovery, muscle glycogen concentrations were, on average, only $73 \mathrm{mmol} / \mathrm{kg}$ wet weight. Jacobs et al. (1982) suggested that the modest glycogen concentrations achieved after $2 \mathrm{~d}$ of recovery were the result of an inadequate carbohydrate intake during the recovery period. Their estimations of the energy intakes of these professional football players, if they are correct, suggest that they were eating almost $600 \mathrm{~g}$ carbohydrate/d. This quantity of carbohydrate should be sufficient to replace the glycogen stores of skeletal muscle in $24 \mathrm{~h}$ (Costill et al. 198I) and so this study highlights the need for accurate assessment of the energy intakes of the subjects in such studies. Finally, while the link between fatigue and glycogen depletion during prolonged submaximal exercise has been firmly established, the relation between glycogen depletion and fatigue during the multiple sprint sports such as football, invites further investigation.

\section{REFERENCES}

Ahlborg, B., Bergström, J., Brohult, J., Ekelund, L-G., Hultman, E. \& Mashio, G. (1967a). Försvarsmedicin 3, 85-99.

Ahlborg, B., Bergström, J., Ekelund, L-G. \& Hultman, E. (1967b). Acta Physiologica Scandinavica 70, $129-142$.

Ahlborg, G. \& Felig, P. (1976). Fournal of Applied Physiology 41, 683-688.

Ahlborg, G. \& Felig, P. (1977). American fournal of Physiology 233, E $188-E_{194}$.

Ahlborg, G. \& Felig, P., Hagenfeldt, L., Hendler, R. \& Wahren, J. (1974). Fournal of Clinical Investigations 53, 1080-1090.

Andersen, P. (1 975). Acta Physiologica Scandinavica 95, 203-305.

Andersen, P. \& Henriksson, J. (1977). Acta Physiologica Scandinavica 99, 123-125.

Astrand, P-O. (1967). Federation Proceedings 26, 1772-1777.

Astrand, P-O. \& Rodahl, K. (1977). Textbook of Work Physiology, pp. 340-341, 2nd ed. New York: McGraw-Hill.

Barany, M. (1967). Fournal of General Physiology 50, 197-218.

Bergström, J., Hermansen, L., Hultman, E. \& Saltin, B. (1967). Acta Physiologica Scandinavica $71,140-150$.

Bergström, J. \& Hultman, E. (1966). Nature 210, 309-310.

Billeter, R., Heizmann, C. W., Howald, H. \& Henny, E. (1981). European fournal of Biochemistry I 16, 389-395.

Billeter, R., Weber, B., Lutz, H., Howald, H., Eppenberger, H. M. \& Jenny, E. (1980). Histochemistry 65, 249-259.

Blom, P. C. S., Vollestad, N. K. \& Hermansen, L. (1984). In Medicine and Sports Science, vol. 17, pp. I 48-160 [P. Marconnet and J. R. Poortmans, editors]. Bassel: Karger.

Boobis, L. H., Williams, C. \& Wootton, S. A. (1983). Journal of Physiology 342, 36-37.

Brooke, M. H. \& Kaiser, K. K. (1970). Archives of Neurology 23, 369-379.

Burke, R. E., Levine, D. N., Zajac, F. E., Tsairis, P. \& Engel, W. K. (197I). Science 174, 709-71 2.

Chen, V., Ianuzzo, C. D. \& Williams, C. (1977). Fournal of Physiology 269, 59-60.

Christensen, E. H. \& Hansen, O. (1939). Skandinavisches Archiv für Physiologie 81, 160-1 75.

Costill, D. L., Coyle, E., Dalsky, G., Evans, W., Fink, W. \& Hoopes, D. (1 977). Fournal of Applied Physiology 43, 695-699.

Costill, D. L., Dalsky, G. P. \& Fink, W. J. (1978). Medicine and Science in Sports 10, I $55^{-1} 5^{8 .}$

Costill, D. L., Sherman, W. M., Fink, W. J., Maresh, C., Witten, M. \& Miller, J. M. (1981). American Fournal of Clinical Nutrition 34, $183 \mathrm{I}-183_{3}$. 
Danforth, W. H. (1965). Foumal of Biological Chemistry 240, 588-593.

Essen, B., Jansson, E., Henriksson, J., Taylor, A. W. \& Saltin, B. (1975). Acta Physiologica Scandinavica 95, 153-165.

Felig, P., Cherif, A., Minagawa, A. \& Wahren, J. (1982). New England fournal of Medicine 306, $895-900$.

Fell, R. D., McLane, J. A., Winder, W. W. \& Holloszy, J. O. (1980). American fournal of Physiology 238, R328-R 332 .

Galbo, H., Holst, N. J. \& Christensen, N. J. (1979). Acta Physiologica Scandinavica ro7, 19-32.

Goforth, H. W. Jr, Hodgson, J. A. \& Hilderbrand, R. L. (1980). Medicine and Science in Sports and Exercise 12, 108A.

Golinick, P. D. (1977). Annals of the New York Academy of Science 301, 64-71.

Gollnick, P. D., Armstrong, R. B., Sauberts, C. W., Sembrowich, W. L., Shepherd, R. E. \& Saltin, B. (1973). Pflugers Archives 344, I-12.

Gollnick, P. D., Ianuzzo, C. D., Williams, C. \& Hill, T. R. (1969). Internationale Zeitschrift für Angewandte Physiologie 27, 257-265.

Gollnick, P. D. \& King, D. W. (I969). American fournal of Physiology 21 6, 1 502-1 509.

Gollnick, P. D., Piehl, K., Karlsson, J. \& Saltin, B. (1975). In Metabolic Adaptation to Prolonged Exercise, pp. 4I6-42 I [H. Howald and J. R. Poortmans, editors]. Basel: Birkhäuser.

Hagenfeldt, L. \& Wahren, J. (1971). In Muscle Metabolism During Exercise, pp. 153-163 [B. Pernow and B. Saltin, editors]. New York: Plenum Press.

Henneman, E. \& Olson, C. B. (1965). Fournal of Neurophysiology 28, $581-598$.

Henriksson, J. (1977). Fournal of Physiology 270, 66 $\mathrm{r}-675$.

Hermansen, L., Hultman, E. \& Saltin, B. (1967). Acta Physiologica Scandinavica 71, 129-1 39.

Hermansen, L. \& Vaage, O. (1977). American fournal of Physiology 233, E422-E429.

Hickson, R. C., Rennie, M. J., Conlee, R. K., Winder, W. W. \& Holloszy, J. O. (1977). Fournal of Applied Physiology 43, 829-833.

Holloszy, J. O. (1984). In Medicine and Sport Science, vol. 17, pp. I 1 1-I 18 [P. Marconnet and J. R. Poortmans, editors]. Basel: Karger.

Holloszy, J. O. \& Narahara, H. T. (1965). Fournal of Biological Chemistry 240, 3493-3500.

Inger, F. (1979). European Yournal of Applied Physiology 40, 197-209.

Ivy, J. L., Costill, D. L., Fink, W. J. \& Lower, R. W. (1979). Medicine and Science in Sports I 1, 6-11.

Jacobs, I., Westlin, N., Karlsson, J., Rasmusson, M. \& Houghton, B. (1982). European Journal of Applied Physiology 48, 297-302.

Jansson, E. (1982). Acta Physiologica Scandinavica 114, $103-110$.

Karlsson, J. \& Saltin, B. (1 971). Fournal of Applied Physiology 3 I, 203-206.

Krogh, A. \& Lindhard, J. (1920). Biochemical fournal 14, 290-363.

MacDougall, J. D., Ward, G. R., Sale, D. G. \& Sutton, J. (I977). Fournal of Applied Physiology 42, I29-132.

McGilvery, R. W. (1975). In Metabolic Adaptation to Prolonged Exercise, pp. 12-30 [H. Howald and J. R. Poortmans, editors]. Basel: Birkhäuser.

Maehlum, S., Hostmark, A. T. \& Hermansen, L. (1977). Scandanivian fournal of Clinical and Laboratory Investigations $37,309-316$.

Newsholme, E. \& Start, C. (1973). Regulation in Metabolism, pp. 126-131. London: Wiley-Interscience Publications.

Nilsson, L. \& Hultman, E. (1973). Scandanavian Journal of Clinical and Laboratory Investigations $32,325-330$.

Padykula, H. A. \& Herman, E. (1955). Fournal of Histochemistry and Cytochemistry 3, $170-195$.

Piehl, K. (1974). Acta Physiologica Scandinavica 90, 297-302.

Piras, R. \& Staneloni, R. (1969). Biochemistry 8, 2153-2160.

Rennie, M. J., Winder, W. W. \& Holloszy, J. O. (1976). Biochemical Journal 1 56, 647-655.

Rowell, L. D. (1974). Physiological Reviews 54, 75-1 59.

Sahlin, K. (1978). Acta Physiologica Scandinavica 455, (Suppl.).

Sherman, W. M. (1983). In Ergogenic Aids in Sport, pp. 3-26 [M. H. Williams, editor]. Champaign: Human Kinetic Publishers.

Sherman, W. M., Costill, D. L., Fink, W. J., Armstrong, L. E., Hagerman, F. C. \& Murray, T. M. (1983). In International Series on Sports Sciences, vol. 17., pp. 312-317 [H. G. Knuttgen, J. A. Volgel and J. R. Poortmans, editors]. Champaign: Human Kinetic Publishers. 
Williams, C. (1981). Fournal of Biosocial Science, 7, Suppl., 103-11 2.

Williams, C., Maughan, R. J., Kelman, R. G., Campbell, D. M. \& Hepburn, D. (1976). Proceedings of the Nutrition Society 35, 135 A.

Williams, C. \& Nute, M. L. G. (1983). British fournal of Sports Medicine 17, 1 52-161.

Williams, C., Patton, A. \& Brewer, J. (1985). Proceedings of the Nutrition Society 44, 28A. 